\title{
Journal of scheduling (2020)
}

\author{
Edmund Burke ${ }^{1} \cdot$ Michael Pinedo $^{2}$
}

Published online: 17 February 2020

(c) Springer Science+Business Media, LLC, part of Springer Nature 2020

During 2019, we completed our 22nd volume. This volume had 41 regular papers, one survey paper, one technical note and two brief communications. The mix of papers spanned many different domains and represented a range across theoretical and practical perspectives. This last year, we have seen again many papers that deal with optimization in deterministic scheduling, focusing on complexity and on algorithms. We also published, of course, papers on stochastic scheduling and papers on scheduling applications.

From its early days, over 20 years ago, the Journal has consistently received novel and innovative contributions from colleagues working in many different fields, including operations research, industrial engineering, manufacturing, artificial intelligence, computer science, operations research and business. The number of high-quality papers in scheduling applications has also been growing steadily over the years. This past year we had, for example, papers in health care and in transportation scheduling (railways as well as aviation). An example of a healthcare application is the paper by Vogl, Braune and Doerner on "Scheduling Recurring Radiotherapy Appointments in an Ion Beam Facility", and an example of a transportation scheduling is the paper by $\mathrm{Xu}, \mathrm{Li}$, Yang and Gao on "An Efficient Train Scheduling Algorithm on a Single-Track Railway System".

Over the years, our journal has published a variety of special issues which represent a broad level of diversity in disciplinary domains. During this past year, we have not published any special issues, but we are expecting to have several special issues in the near future. Typically, these special issues are selected papers from one of the multiple conferences and workshops that take place every year in the vibrant field of scheduling. Examples of events that have had associated special issues of the Journal include the workshop on Models and Algorithms for Planning and Scheduling (MAPSP) and the Multi-Disciplinary Scheduling-Theory

Edmund Burke

edmund.burke@leicester.ac.uk

1 University of Leicester, Leicester, UK

2 Department of Operations Research, Stern School of Business, New York, NY, USA and Applications (MISTA) conference. A workshop that has had a particularly close partnership with the Journal is the biennial New Perspectives in Scheduling Theory event being held in Aussois in 2020. This is the 15th workshop in this series. The first one was held in Dagstuhl in 1995 and had the title "Workshop on Scheduling in Computer and Manufacturing Systems". Over the years, several special issues of the Journal have been devoted to this series of workshops.

During 2019, the Journal has continued to build its reputation for publishing high-quality research across disciplinary boundaries. Some key indicators of the Journal's high standing can be outlined as follows.

- Our Thompson Reuters impact factor has increased to 1.598.

- In 2019, we accepted 36 regular papers from 248 new submissions.

- The acceptance rate of the Journal for 2019 was around $15 \%$.

- The average time between submission and the first decision in 2019 was 84 days.

We are pleased to see that the number of article downloads for the Journal has increased significantly over the years. The figures are:

\begin{tabular}{ll}
\hline 2014 & 31,986 \\
2015 & 38,660 \\
2016 & 42,508 \\
2017 & 47,943 \\
2018 & 51,120 \\
2019 & 54,895 \\
\hline
\end{tabular}

We are particularly pleased to see an increase of just under 23,000 downloads since 2014.

We normally finish our annual Editorial with a word of gratitude towards all those who have contributed their valuable time to the Journal over the previous year. We would like to offer a special thank you to our 54 Associate Editors 
who come from many diverse backgrounds, including Engineering Schools, Business Schools, Computer Science and Mathematics departments. They play a key part in the success of the Journal. Our reviewers also have a critical role in maintaining and improving the high standards of the Journal, and we are grateful for their efforts. The editorial team at Springer continues to provide a very high level of sup- port. Particular thanks should be given to Mangayarkarasi Lakshmiram, Ramya Murali, Sabarinathan Gunasekaran, Subhashini Gopal and Matthew Amboy.

Publisher's Note Springer Nature remains neutral with regard to jurisdictional claims in published maps and institutional affiliations. 